\title{
De Mato Grosso a Chiquitos: migraciones furtivas en la frontera luso-española
} From Mato Grosso to Chiquitos: Furtive Migrations in the Spanish-Portuguese Border ${ }^{1}$

Cecilia Martínez ${ }^{*}$ **

\section{RESUMEN}

En el siglo XVIII, a partir del descubrimiento de oro, cientos de portugueses acompañados de miles de esclavos africanos y afrodescendientes, se asentaron en Mato Grosso. Al otro lado del río Paraguay, en la gobernación de Chiquitos, esto se reflejó en una sigilosa pero incesante afluencia de fugitivos - negros esclavos o libres, de origen africano o criollo, mineros, peones de haciendas, soldados desertores, y también de portugueses y criollos blancos -, que encontraban en las tierras ubicadas al otro lado de la frontera una vía de escape a circunstancias variadas. El artículo analiza especialmente la fuga de los esclavos negros, a partir de la evidencia tardo-colonial registrada del lado español de la frontera. Enmarcado en el estudio de la frontera luso-española en la última etapa del período colonial, este trabajo se detiene en la migración furtiva desde los dominios de Portugal a los de España.

Palabras clave: migración; negros; esclavos; Mato Grosso; fugitivos.

\section{Abstract}

As a consequence of the discovery of gold, during the 18th century, hundreds of Portuguese and blacks settled down in Mato Grosso. On the other side of the Paraguay river, in the province of Chiquitos, these changes were reflected in a continuous but stealthy fugitive's migration. A large number of blacks - slaves, freedmen and free, African and creoles, miners, renegade soldiers -, but also Portuguese and white criollos, found in those neighbouring territories a way out of varied circumstances. Spanish late-colonial information is analysed in order to describe illegal migration. Since great number of registered cases correspond to runaway slaves, this paper focuses on the study of the slave fugitives and offers a complementary study about slavery in Mato Grosso, which is a prolific research topic specially concerning the quilombos and the interethnic relations with indigenous peoples, but less dedicated to the migration slaves' strategy to reach freedom.

Keywords: migration; blacks; slaves; Mato Grosso; fugitives.

\footnotetext{
* Universidad de Buenos Aires (UBA), Buenos Aires, Buenos Aires, Argentina.

** Consejo Nacional de Investigaciones Científicas y Técnicas (Conicet), Buenos Aires, Buenos Aires, Argentina. ceciliagmartinez@gmail.com <https://orcid.org/0000-0001-6599-5123>
} 


\section{LA TRAMA INCOMPLETA}

En el siglo XVIII, a partir del descubrimiento de oro en Mato Grosso, cientos de colonizadores provenientes de San Pablo, acompañados de esclavos afrodescendientes, que emplearon como mano de obra minera y agropecuaria, se asentaron en el floreciente arrabal de Cuiabá. ${ }^{2}$ Al otro lado del río Paraguay, la estrepitosa amenaza bandeirante del siglo anterior dio paso a la incesante pero sigilosa afluencia de personas que buscaban en la orilla occidental y tierra adentro una vía de escape a variadas circunstancias acuciantes.

En estas páginas se describe este fenómeno a partir de evidencia producida del lado español de la frontera, en Chiquitos, Santa Cruz de la Sierra y Charcas. Se presenta un relevamiento de la totalidad de los casos registrados junto con un análisis estadístico y se analiza especialmente la información concerniente a los esclavos negros. Los documentos analizados forman parte del acervo de Mojos y Chiquitos del Archivo y Biblioteca Nacionales de Bolivia (ABNB MyCh), fondos Gabriel René Moreno (GRM) y Audiencia de La Plata (ALP), y del Archivo General de la Nación de Argentina (AGN), legajos del Gobierno de Chiquitos y del Gobierno de Santa Cruz de la Sala IX (Gobierno colonial), junto con otros de la colección Andrés Lamas (AGN Lamas).

En lo que respecta a los esclavos fugitivos, este trabajo complementa los numerosos estudios sobre el esclavismo en Mato Grosso. Al respecto, si bien los investigadores brasileños reconocen una variedad de opciones para la fuga -quilombos, poblaciones indígenas montaraces, traspaso a los dominios españoles, vida autónoma en el monte-, la migración al reino vecino es la estrategia que menos llamó su atención en comparación con la etnogénesis y dinámica quilombola y las relaciones interétnicas con los indígenas (Souza Lordelo, 2011; Rodrigues, 2016a).

La centralidad de los estudios sobre quilombos y mocambos se debe en gran parte al impulso que ese tema recibió en el centenario de la ley de abolición de la esclavitud en 1988, que coincidió con la disputa de territorios con el Estado y con actores blancos por parte de grupos de "remanescentes" de esclavos y libertos (Arruti, 1997). Por eso, desde fines de la década de 1980, el estudio de su historia ocupó un lugar importante en la escena historiográfica y antropológica brasileña. ${ }^{3}$

La disponibilidad de información también contribuyó a que el tema de los quilombos tuviera un lugar privilegiado en las investigaciones sobre los esclavos fugitivos de Mato Grosso. Las fuentes analizadas habitualmente forman parte de acervos de documentos coloniales de Brasil y Portugal. Entre las 
numerosas investigaciones referidas al tema, se destaca la referencia al quilombo Grande o Piolho, una réplica de reino africano enclavada en el monte, con su realeza y sus jerarquías, paradigma de la resistencia de los negros de Mato Grosso. Informes y crónicas permiten conocer con inusual detalle las acciones y formas de organización de actores cuya posición subalterna en la sociedad colonial suele dificultar la reconstrucción de su historia (Coelho, 1850; Amado; Anzai, 2006, p. 137-140; Rodrigues, 2016b, nota 2).

En significativo contraste, las referencias en los documentos portugueses sobre los fugados a tierras españolas se limitan a listas de nombres, dueños y ocupaciones de aquellos esclavos cuya fuga se frustró. Los estudios basados en estos documentos reflejan cómo las evasiones afectaban a los propietarios de esclavos y las medidas que tomaban las autoridades de la capitanía al respecto. En definitiva, aportan información desde la perspectiva del actor social dominante, pero no un estudio sobre los posibles destinos de los fugitivos o la forma en que huían. Los datos se diluyen en la frontera y los destinos de los fugitivos quedan truncos. Por eso, los datos provenientes del lado español resultan reveladores porque aportan información hasta ahora inexplorada sobre la huida de los esclavos de Mato Grosso. ${ }^{4}$

\section{La frontera luso-española en el Alto Paraguay}

A los efectos de poner en contexto los datos, se impone una caracterización de la frontera imperial que fue a la vez escenario, condición y resultado de estos movimientos migratorios.

Desde el siglo XVI, a instancias de la información que les aportaban guías, informantes y colaboradores indígenas, los conquistadores portugueses forjaron en su imaginario la idea de la "Ilha Brasil" como unidad territorial a conquistar: una gran masa de tierra delimitada por la costa atlántica, los ríos Amazonas y Madera, unidos por una inmensa laguna al río Paraguay, y en el sur por el río Uruguay hasta el Río de la Plata. La ausencia de ocupación española facilitó el objetivo, porque la mayor parte de los territorios que la Compañía de Jesús colonizó en Paraguay, Mojos y Chiquitos no se superponía con los de la Ilha Brasil (Sotomayor, 2013).

A principios del siglo XVIII los portugueses habían avanzado considerablemente en la ocupación y explotación de las tierras interiores del Brasil. Los bandeirantes, derrotados en la Guerra de los Emboabas (1708-1709) y expulsados de San Pablo se internaron tierra adentro y en 1718 descubrieron oro en Cuiabá. Entonces comenzó la colonización de Mato Grosso que derivó en la 
relación fronteriza luso-española en el Alto Paraguay. Esta contaba con antecedentes que se remontan a 1695-1696, cuando los bandeirantes asaltaron los pueblos de San Rafael y de San Xavier de Chiquitos. Pero en el siglo XVIII, los ecos del nuevo enclave de explotación aurífera llegaron al otro lado de la frontera en forma de expediciones comerciales pacíficas y de traspasos silenciosos de mercancías y de personas (Mendonça, 1985).

La creciente cantidad de colonos y esclavos demandaba un volumen de alimentos que las capitanías portuguesas de Grão Pará y de San Pablo, con las que Mato Grosso estaba conectada por el Norte y por el Sur, respectivamente, no lograban satisfacer. En busca de abastecimiento ensayaron la posibilidad de comerciar con los territorios españoles ubicados al oeste. A mediados de 1740 llegó a la campaña del pueblo de San Rafael de Chiquitos una expedición conocida como "bandeirinha", con la intención de abrir una ruta de intercambio con Chiquitos, Santa Cruz y Charcas y de conocer los dominios españoles con miras a la negociación de un tratado de límites que legitimara la ocupación portuguesa (Cortesão, 1952; Carvalho, 2011; Pereira et al., 2012; Sotomayor, 2013). Con el mismo propósito se internaron en Mojos en 1742 y 1743 (Block, 1997, p. 94).

Estas visitas portuguesas encendieron la alarma de los jesuitas y de las autoridades españolas. En respuesta, en 1743 y en 1746 se fundaron tres pueblos en Mojos, en la margen oriental del río Guaporé (Santa Rosa, San Miguel y San Simón), y en Chiquitos los pueblos más orientales de la provincia: San Ignacio (1748), Santiago (1754), Santa Ana (1755) y Santo Corazón (1760), que, como se verá en los siguientes apartados, pasaron a ser los receptores de la migración furtiva desde Mato Grosso.

Con estos hitos, comenzó un ciclo de acciones y reacciones en el espacio fronterizo luso-español del Alto Paraguay y el Guaporé. ${ }^{5}$ En 1748 se creó la capitanía de Mato Grosso como una jurisdicción independiente de la de San Pablo y en 1752 se fundó su capital, Vila Bela, en la costa del río Guaporé. De esta manera se jerarquizaba la salida de oro por el Guaporé-Madeira, mucho más ágil y segura que la paulista cuyos monções combinaban la vía fluvial y la terrestre, frecuentemente asediada por indígenas montaraces.

En 1750 el Tratado de Madrid legitimó el derecho de Portugal a las tierras ubicadas al este de los ríos Uruguay, Paraguay y Guaporé, pero su aplicación se malogró. Esta circunstancia junto con el cambio de rey en España llevó a que en 1760 ambas coronas acordaran la anulación del tratado. La llegada de Carlos III al trono también significó el abandono de la política neutral en los conflictos europeos. Estos sucesos repercutieron sensiblemente en la relación 
fronteriza entre Mato Grosso y las provincias jesuíticas. Hubo conflictos por la forma en que los jesuitas debían proceder a abandonar los pueblos que habían fundado en la costa portuguesa del río Guaporé y por la resistencia de los portugueses a hacer lo propio con el pueblo de Santa Rosa una vez anulado el Tratado de Madrid. La tensión creció cuando, en el marco del conflicto luso-español en la Guerra de los Siete Años, el virrey del Perú dio la orden de expulsar a los portugueses de aquel pueblo. Los españoles intentaron bloquear el acceso fluvial a Vila Bela y el capitán general de Mato Grosso respondió atacando la misión de San Miguel y tomando prisioneros a indios y jesuitas.

Pero en Chiquitos, donde los asentamientos más próximos a la frontera estaban ubicados unas leguas tierra adentro, estas tensiones no se tradujeron en enfrentamientos abiertos. En cambio, en esta zona, la década de 1760 estuvo signada por otro tipo de conflicto: la guerra chiquito-guaycurú, un enfrentamiento que comenzó en 1763, entre la milicia de flecheros de las reducciones jesuíticas y los jinetes eyiguayegui que atacaban las estancias del pueblo de Santo Corazón en busca de ganado y otros bienes (Martínez, 2017b). Recién se logró la pacificación en la primera mitad de 1790, por lo que esta guerra tuvo mucho que ver con la ausencia de una ocupación efectiva de la costa del lado español. Por su parte, los portugueses encararon la fundación casi simultánea de varios asentamientos en la zona a los efectos de defender los monções paulistas que abastecían Cuiabá y otras villas matogrossenses de los ataques guaycurú y de formalizar la ocupación de esas tierras ante la inminente firma de un nuevo tratado de límites. Así, erigieron el Forte de Nova Coimbra (1775), la Vila Maria do Paraguay (1778, actual Cáceres) y Albuquerque (1778). Como contrapartida los españoles fundaron la Villa Real de la Concepción en 1773, y más tarde el fuerte de Borbón (1792), el de San Carlos (1794) y el de San José (1797), en el río Apa, todos dependientes de la gobernación de Paraguay (Cleret de Langavant, 2012; Sena, 2012).

Junto con estas fundaciones, durante los gobiernos de Luis Pinto de Souza Coutinho y Luis de Albuquerque, los portugueses de Mato Grosso adoptaron una política deliberada de atracción de indígenas de Mojos y de Chiquitos a las villas y poblados portugueses y de promoción del contrabando con los dominios españoles. Del lado español, la expulsión de los jesuitas en 1768 y su reemplazo por curas doctrineros favoreció el éxito de ambas empresas. Es decir que, junto con mercancías y sobre todo con el ganado que los curas de Chiquitos les vendían a los hacendados portugueses, también circulaban personas de un lado a otro de la frontera: curas, hacendados, comerciantes, indígenas y esclavos negros (Martínez, 2018a, cf. Carvalho, 2012). 
Para la misma época un nuevo tratado de límites firmado en 1777 en San Ildefonso reconocía la ocupación portuguesa al este del Alto río Paraguay y del Guaporé. A pesar de la concordia que significaba esta definición, las dos coronas ibéricas no pudieron evitar las tensiones y complicaciones que acarreó el juego de alianzas europeo y la revolución francesa. España fracasó en la guerra contra la República y firmó la paz de Basilea (1795) en la que se selló una alianza con Francia contra Gran Bretaña y, por lo tanto, contra Portugal, lo que repercutió en sus territorios coloniales. En 1801 tuvo lugar un conflicto entre ambas monarquías ibéricas, que comenzó el 27 de febrero y concluyó el 6 de junio. Pero la distancia con las colonias hizo que sus repercusiones se desarrollaran luego de la Paz de Badajoz firmada en Europa. Esta referencia a sucesos europeos es necesaria para comprender las escaramuzas que tuvieron lugar en el río Paraguay, donde el gobernador Lázaro de Ribera envió una expedición fluvial para expulsar a los portugueses de Nueva Coímbra entre el 16 y el 25 de septiembre de 1801. Como contrapartida, el 31 de diciembre, los portugueses destruyeron el fuerte español de San José en el río Apa (Maeder, 1986).

En suma, estos acontecimientos diplomáticos no pueden ser soslayados a la hora de interpretar los datos referidos a la frontera luso-española altoparaguayense. Por lo demás, dos singularidades se desprenden de esta contextualización. La primera es que, a diferencia de lo que sucedió en la jurisdicción de Paraguay (en la guerra guaranítica y luego en 1801) y en la de Mojos (en 1763), en la porción de la frontera correspondiente a Chiquitos no hubo ningún conflicto armado. Si bien del lado portugués se fundaron villas y fuertes, del lado español no ocurrió lo mismo. La amenaza guaycurú desalentó la instalación de pueblos de indígenas en la orilla del río, mientras que las condiciones ambientales y la lejanía con Santa Cruz y Charcas no colaboraron con una eventual colonización criolla de la costa. Estas condiciones permiten imaginar que, más allá de la porosidad de todo espacio de frontera, la porción lindera entre Chiquitos y Mato Grosso era un lugar de fácil ingreso al dominio español para quienes salían furtivamente del de Portugal. A continuación, presentaré los casos registrados del lado español y analizaré especialmente aquellos concernientes a negros esclavos.

\section{Presentación de los Casos}

Los documentos sobre el período colonial tardío en Chiquitos de los fondos analizados aquí abarcan desde 1740 hasta 1801. Las referencias sobre personas de los dominios de Portugal que se pasaron a los de España por la vía de 
Chiquitos suman treinta y una. La siguiente tabla resume el contenido de los documentos referido a cantidad de personas, status étnico, condición de libre o esclavo, sexo, lugar de procedencia y lugar donde se registró su llegada al dominio español.

Los casos están ordenados cronológicamente. Las fechas corresponden al momento en que tuvo lugar la migración (no al momento en que fue registrada). Los criterios que se siguieron para distinguir entre indígenas, negros y blancos están explicados en el apartado analítico. Allí donde no fue posible establecer si se trataba de negros libres o de esclavos, las celdas de ambas categorías fueron combinadas.

Tabla 1 - Cantidad de personas, status étnico, condición de libre o esclavo, sexo, lugar de procedencia y lugar donde se registró su llegada al dominio español (1740-1801)

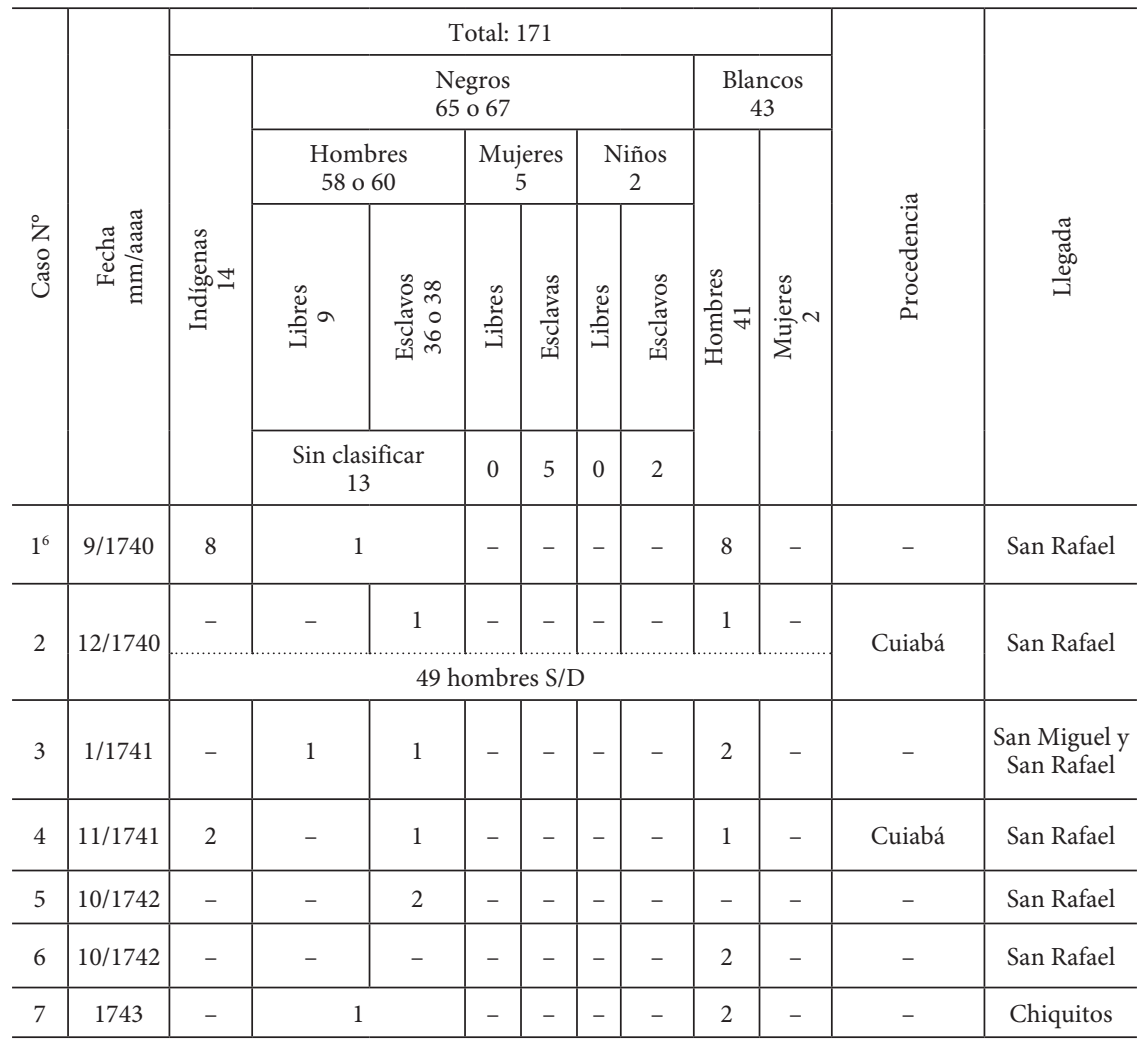


continuación

\begin{tabular}{|c|c|c|c|c|c|c|c|c|c|c|c|c|}
\hline $8^{7}$ & $\begin{array}{c}1756 \text { o } \\
1757\end{array}$ & 1 & \multicolumn{2}{|c|}{1} & - & - & - & - & - & - & Cuiabá & San Juan \\
\hline $9^{8}$ & 1761 & - & 1 & - & - & - & - & - & - & - & $\begin{array}{c}\text { Destacamento } \\
\text { de } \\
\text { Diamantes } \\
\end{array}$ & - \\
\hline $10^{9}$ & 1769 & - & - & 2 & - & - & - & - & - & - & - & San Ignacio \\
\hline $11^{10}$ & $11 / 1771$ & - & - & 1 & - & - & - & - & - & - & - & Santa Ana \\
\hline 12 & $1 / 1772$ & - & \multicolumn{2}{|c|}{2} & - & - & - & - & - & - & Cuiabá & San Juan \\
\hline 13 & $9 / 1772$ & - & - & 1 & - & - & - & - & - & - & Vila Bela & Santa Ana \\
\hline 14 & $10 / 1772$ & - & \multicolumn{2}{|c|}{1} & - & - & - & - & - & - & Cuiabá & Santa Ana \\
\hline 15 & $10 / 1772$ & - & - & - & - & - & - & - & 12 & - & - & San Ignacio \\
\hline $16^{11}$ & 1775 & - & - & - & - & - & - & - & 1 & - & - & San Juan \\
\hline $17^{12}$ & 1779 & - & \multicolumn{2}{|c|}{5} & - & - & - & - & 3 & - & - & San Juan \\
\hline $18^{13}$ & $9 / 1780$ & - & $\begin{array}{c}\text { Varios } \\
\mathrm{s} / \mathrm{n}\end{array}$ & - & - & - & - & - & 1 & 1 & - & Santa Cruz \\
\hline $19^{14}$ & $6 / 1781$ & 2 & - & - & - & - & - & - & 1 & 1 & - & San Juan \\
\hline 20 & $7 / 1781$ & - & 1 & - & - & - & - & - & - & - & - & San Juan \\
\hline $21^{15}$ & 1781 & - & - & 1 & - & - & - & - & - & - & - & San Xavier \\
\hline $22^{16}$ & $2 / 1782$ & - & \multicolumn{2}{|c|}{2} & - & - & - & - & - & - & - & San Ignacio \\
\hline $23^{17}$ & 1782 & - & - & 3 & - & - & - & - & - & - & - & San Xavier \\
\hline $24^{18}$ & 9/1782 & - & $\begin{array}{l}\text { Un } \\
\text { grupo } \\
\text { s/n }\end{array}$ & - & - & - & - & - & - & - & - & Santa Ana \\
\hline $25^{19}$ & $10 / 1782$ & - & - & - & - & - & - & - & 7 & - & - & Santa Ana \\
\hline $26^{20}$ & $7 / 1796$ & - & - & 3 & - & - & - & - & - & - & Cuiabá & San Juan \\
\hline 27 & $7 / 1796$ & - & - & 10 o 12 & - & - & - & - & - & - & - & $S / D$ \\
\hline $28^{21}$ & 9/1796 & - & 2 & 2 & - & 3 & - & - & - & - & - & San Rafael \\
\hline $29^{22}$ & $9 / 1801$ & - & - & 3 & - & - & - & - & - & - & - & Santa Ana \\
\hline $30^{23}$ & $11 / 1801$ & - & - & 5 & - & 2 & - & 2 & - & - & Vila Bela & Santa Ana \\
\hline $31^{24}$ & $\begin{array}{l}\text { Entre } \\
1801 \mathrm{y} \\
1806\end{array}$ & 1 & 4 & - & - & - & - & - & - & - & - & Santa Ana \\
\hline
\end{tabular}




\section{LOS DATOS DESAGREGADOS}

\section{Aspectos cuantitativos, taxonómicos y cronológicos}

Estos treinta y un casos muestran que a lo largo de 66 años hubo intentos continuos de traspasar la frontera entre Mato Grosso y Chiquitos. En total suman 171 personas. Además, hubo otras, mencionadas en los relatos de los fugitivos, cuya entrada no fue registrada: por ejemplo, cincuenta esclavos que huyeron junto con los del caso 30, pero que se dispersaron al ser perseguidos por un grupo de soldados. Si además tenemos en cuenta que en la mayoría de los casos los fugitivos aparecen en estancias y pueblos de la provincia luego de meses de errar en el monte, y que existen tres grandes intermitencias en el registro que no necesariamente reflejan la suspensión de las migraciones, este registro debe ser considerado una muestra de un conjunto más grande.

De las 171 personas, 65 o 67 (dependiendo de cuántos hayan sido los del caso 27) son descritas con términos que refieren de forma explícita ("negro", “mulato", "pardo", “moreno") o tácita ("esclavo", “criado" o "cimarrón”) ${ }^{25}$ a su ascendencia negra. De los nueve libres, dos son militares desertores (caso 9, Simplicio Godoy y caso 28, Juan Silva Noguera). Los demás son consignados como "negros libres". Luego, 43 o 45 son "esclavos" o "criados"; cinco de ellos son mujeres y dos son niños. Los 13 restantes son de status inclasificable porque la única precisión que tenemos es que son "negros", "negro portugués" o "negro mozo" o porque, como en el caso 7, la información al respecto es contradictoria.

Luego, 41 individuos son "hidalgos" (caso 1), "portugueses" (casos 2, 15, 17, 18, 24), "portugueses hidalgos" (caso 3), "pedestres" (caso 15) o "desertor portugués" (caso 19). Los de los casos 18 y 19 llegan con sus esposas. Para todos ellos adoptamos, por defecto, la categoría "blancos", para distinguirlos de los "negros", dado que el registro es explícito al referirse a castas y africanos, y por lo tanto asumimos que los "portugueses" no lo son. Entre ellos hay ocho estancieros instalados en las tierras próximas a los ríos Paraguay y Jaurú (casos 19 y 25), 23 prófugos (casos 1, 3, 4, 6, 16, 17, 18, 19), de los cuales dos son mujeres, y 12 misceláneos: dos hombres referidos como "don" y 10 pedestres (caso 15).

Por último, 12 son "naturales" (caso 1) e "indios" (casos 4, 8 y 19). Algunos de ellos regresaron a Chiquitos luego de haber estado en Cuiabá, de otros no conocemos la procedencia. 
Esta clasificación muestra que, si restamos los 49 hombres del caso 2 del total, cuya condición étnica y status de libres o esclavos desconocemos, un poco más de la mitad de los restantes (112) eran negros (65 o 67). La mayoría eran esclavos (43 o 45); su número iguala al de los blancos (43) y podría superarlo si consideramos que entre los negros inclasificables por falta de datos había esclavos.

Más allá de estas distinciones la muestra no deja lugar a dudas de que cruzar la frontera era una empresa eminentemente masculina. Solo 7 de 171 eran mujeres. La del caso 18, blanca, es fugitiva de su esposo: Rosalía Joaquina, casada en Cuiabá, se fugó con otro hombre con quien se casó en Santa Cruz. En cambio, la del caso 19 se fugó con su esposo Lorenzo Joaquín Acosta, prófugo de la justicia por herir a un soldado. De las tres esclavas del caso 28, dos conformaban sendos matrimonios y la tercera era la hija de uno de aquellos. Todos llegaron como parte de las pertenencias de un blanco fugitivo. Las dos esclavas del caso 29 llegaron con sus respectivos bebés y junto con cinco esclavos hombres.

Ahora bien, al tratamiento taxonómico y cuantitativo de los datos podemos sumarle una consideración cronológica y geográfica. Durante la década de 1740 (casos 1 a 6), San Rafael era la puerta de entrada a Chiquitos porque era el pueblo más oriental y más cercano al camino que conectaba con Cuiabá. Esto cambió a partir de 1748. Con la fundación de San Ignacio, Santiago, Santa Ana y Santo Corazón las entradas comenzaron a ser registradas en esos pueblos (casos 8, 10, $11,12,13$ y 14). Hacia finales de la década de 1770 y en los primeros años de la de 1780, se intensificaron las entradas por San Juan (casos 16, 17, 19 y 20). Esta vía más meridional de entrada a Chiquitos debió estar relacionada con las fundaciones de Vila Maria do Paraguay (1778), Nueva Coímbra (1775) y Albuquerque (1778) en la costa oriental del Paraguay. Más tarde, pocos fugitivos llegan por San Juan (caso 21), mientras que la mayoría aparece por Santa Ana (casos 24, 25, 29, 30 y 31), San Xavier (casos 23 y 26), San Ignacio (caso 22), y San Rafael (caso 28), o sea, por el norte. Muchos provienen de Vila Bela e informan sobre la instalación de estancias portuguesas en el Jaurú y sobre extracción de minerales en el cerro Guarayu. En efecto, estas actividades debieron redundar en la intensificación de las entradas por el arco septentrional.

\section{Aspectos cualitativos: la modalidad de las fugas}

Tanto blancos como negros buscaban la libertad al traspasar la frontera. Los primeros de manera preventiva al huir de la justicia, los segundos de forma 
reparatoria. Es preciso aclarar, sin embargo, que ambos imperios acogían la esclavitud en sus territorios. De ahí que la expectativa de libertad estuviera puesta en la lejanía con respecto al amo o a la justicia real más que en el cambio de jurisdicción. Por eso, la competencia territorial entre ambos imperios (a la que me referiré luego), fue determinante para el destino de los fugitivos.

Muchos esclavos apelaban al sentido de justicia o alegaban fugarse por malos tratos y mala alimentación. Miguel Albis Teixeira (caso 20) huyó porque su dueño no cumplió con liberarlo cuando terminara de pagar el costo de su compra. Los tres esclavos del caso 26 huyeron porque no los alimentaban, no les daban ropa y los hacían trabajar demasiado. En la misma situación estaban los 10 o 12 del caso 27. También los cinco negros del caso 30 (y los cincuenta que iban con ellos), alegaron malos tratos, falta de comida y trabajo excesivo "como de ordinario les sucede a todos los esclavos de Portugal por cuya razón se habían juntado tantos para huirse".

Otros apelaban a una curiosa retórica. Es el caso de Antonio Lemes (caso 7), por ejemplo (cuyo estatus es indefinido porque la información es contradictoria). En 1743 se presenta ante la Real Audiencia de la Plata a pedir que se lo reconozca como el hombre libre que era en Mato Grosso. Pero el tribunal determinó que era un esclavo fugitivo y ordenó que fuera rematado como tal. Esta sentencia es llamativa porque la legislación vigente no hacía referencia a los esclavos que provenían de otros dominios (Leyes de Indias Libro VII, Título 5, "De los Mulatos, Negros, Berberiscos e hijos de Indios"). Las razones del tribunal son tan difíciles de elucidar como la veracidad del relato de Lemes. Pero lo que llama la atención es que su relato contiene elementos que aparecen en los de otros negros fugitivos. Lemes dijo que era empleado de dos portugueses, a quienes acompañó sin saber a dónde se dirigían. Sus empleadores murieron en un ataque indígena y él anduvo errante hasta que llegó a un pueblo de Chiquitos. Es decir que no había tenido la intención de cruzar la frontera y que quedó a merced de circunstancias fortuitas. Algo similar relató Antonio (caso 4), esclavo, quien se fue de Cuiabá sirviendo al hermano de su difunto amo, que huía de la justicia por vengar la muerte de aquél. Pero este murió en el camino y Antonio logró llegar a un pueblo luego de errar por el monte. Nuevamente, el amo decide la huida, pero también muere en el camino; ambos pasaron la frontera sirviendo a sus patrones, y al morir éstos quedaron liberados accidental e involuntariamente. La anuencia del dueño y la desventura como resultado del servicio al amo vuelven a aparecer en el relato de Juan Perera (caso 21). Había cometido un asesinato en cumplimiento de su trabajo 
como peón de hacienda; su dueño, al advertir que no podría evitar que lo atrapen, le dio un arma y lo dejó huir.

La inversión de la relación entre huida, consentimiento, obligaciones con el dueño, vida/muerte del amo confirman aquella estructura argumentativa. En los casos 20 y 28 los esclavos son parte de las pertenencias de fugitivos blancos y se los llevaron para resguardar su derecho sobre ellos. En ambos casos, la aprobación del amo para fugarse seguida de su supervivencia al otro lado de la frontera, renovó la condición de esclavo en la nueva jurisdicción. Por eso la situación inversa - el consentimiento del amo seguido de su muerte o de su ausencia - resulta en lo contrario: la libertad.

Con respecto a la modalidad de las huidas, debemos considerar, en primer lugar, la recurrente aparición de los fugitivos en los pueblos o en las estancias: es una constante el extravío en el monte y la trashumancia, que duraban hasta que fortuitamente se encontraban con algún indígena que les indicaba el camino. Llegaban solos o en grupos reducidos: de a dos (casos 10, 12, 22, 5), o de a tres (casos 23, 26, 29), y solo de forma excepcional, de a cinco (caso 30). De esto podría deducirse una modalidad de fuga acotada en número. Pero también varios relatos señalan que los planes de huida habían sido concebidos por grupos más grandes (cincuenta en el caso 30, trece o quince en los casos 26 y 27) que fueron perseguidos y dispersados. Entonces, muchas pueden haber sido planeadas en grupos numerosos que luego se dispersaron. A diferencia de las huidas a los quilombos dentro del Brasil, que solo requerían sortear una frontera interior, aquí se sumaba el traspaso de un límite fluvial entre ambos imperios que se encontraba cada vez más vigilado y militarizado (Sena, 2013; Rodrigues, 2016a).

Como fue señalado, estos casos deben ser considerados como la parte visible de un conjunto seguramente mayor cuyo destino desconocemos. La provincia de Mojos pudo haber sido uno de ellos. En efecto, la presencia de negros fue considerable en esa gobernación: 51 esclavos fugitivos en Magdalena en 1770, 24 en Loreto en 1772, 46 en Exaltación en 1776. Además, en 1790 fue descubierta en la margen del río Baures la vivienda de un quilombo no muy distante de la misión de Magdalena (Meireles, 1989, p. 178).

Por otra parte, los casos 4, 8, 19 y 31 son explícitos con respecto a la participación de indígenas en las huidas. El caso 19 se refiere al soldado desertor Juan Perera, pero los otros tres muestran que hacían causa común con los esclavos negros en procura de la libertad (8), o bien porque eran originarios de la provincia y conocían el camino de regreso ( 4 y 31), jugaron un papel importante en las fugas. Aunque la cantidad de ejemplos es reducida, resulta 
significativa a la luz del énfasis que últimamente se puso en estudiar las relaciones interétnicas entre negros e indígenas en los quilombos del Brasil colonial, y especialmente en los de Mato Grosso. ${ }^{26}$ La comparación es inevitable pues se trata de una relación interétnica en una situación de fuga. Luego, las diferencias son evidentes. Mientras que los quilombos ofrecían condiciones para la convivencia de indígenas y esclavos y para una eventual "etnogénesis", no está claro si los negros fugitivos se instalaron en los pueblos de Chiquitos. Algunos documentos señalan que varios fugitivos fueron enviados a Santa Cruz; en cambio, no hay referencias explícitas al avecindamiento de esclavos desertores. Si lo hicieron, debió ser muy distinta a la convivencia en un quilombo, dada la presencia de actores coloniales. El borrador de un reglamento redactado por el gobernador Barthelemí Berdugo que data de 1780 podría indicar su integración. Decía que "los negros y mulatos se tienen en la clase de indios en lo que concierne a los castigos que les toquen" (ABNB MyCh GRM 39 XXXIV), lo que implicaba la paridad punitiva entre indígenas, mestizos y negros en los pueblos de misión, y suponía su sujeción al cabildo indígena. La homologación de los negros y mulatos con los indígenas podría sugerir que la presencia de los primeros era tan usual que ameritaba regular su estatus punitivo. Si bien esta inferencia es razonable, lo dicho no basta para darla por certera. Por otro lado, si tenemos en cuenta que la reglamentación vigente a lo largo de todo el período tardo-colonial desalentaba la permanencia de castas y de blancos en las reducciones indígenas, se entiende que se evitara mencionar la presencia de negros.

\section{El registro en su contexto}

El registro de la llegada de los fugitivos es inescindible de la problemática limítrofe que preocupaba a las autoridades coloniales españolas. Como señalé, se advierten intermitencias en la disponibilidad de datos que parecen tener un correlato directo con ciertos hitos de la relación fronteriza que caractericé antes de presentar los datos.

El primer tramo de casos corresponde a los primeros años de la década de 1740. Coincide con las expediciones desde Mato Grosso hacia el oeste en busca de abastecimiento y vínculos comerciales con los dominios españoles. Las entradas desde Portugal de este primer conjunto de casos se refieren a visitas que hasta el momento no fueron mencionadas en la literatura sobre la frontera luso-española. En ellos se destaca la intransigencia de los jesuitas en 
impedir el paso de los portugueses. Todos los blancos que llegaron a San Rafael fueron rechazados ( $\operatorname{casos} 1,2,3,5$ y 6), mientras que los esclavos fugitivos que aparecieron en los pueblos o estancias de la provincia fueron enviados al gobernador de Santa Cruz (casos 4, 7 y 8 ) o castigados para que no regresaran.

Un segundo momento de abundancia de evidencia es la década de 1770 y los primeros años de la siguiente y abarca los casos 8 a 25. Vale aclarar que el traspaso del caso 8, si bien tuvo lugar en 1756 o 1757, fue registrado en el año 1772. Lo mismo ocurre con el caso 9, cuyo protagonista relató en 1781 haber cruzado la frontera veinte años atrás. El caso 10, de 1769, aparece en el reglamento del gobierno temporal que reemplazó el régimen jesuítico. Si bien corresponde a la década de 1760, nos tomaremos la licencia de incluirlo en este segundo conjunto de casos.

La década de 1770 es un momento de álgido dinamismo en la frontera. Es cuando el reemplazo de los jesuitas por los curas doctrineros cristaliza en prácticas inéditas como el contrabando de ganado desde las estancias de los pueblos a haciendas del reino de Portugal. Esto motivó la denuncia de los indígenas y la indagación de las autoridades laicas a través de circulares de consulta a los cabildos e interrogatorios a los prófugos. En este contexto, los negocios de los curas con los portugueses redundaban en la afluencia de fugitivos. Francisco Camargo (caso 16) llegó al pueblo de San Juan para comprar ganado, pero terminó quedándose. En el mismo pueblo también se contaba que era frecuente que llegaran negros con correspondencia relativa a la compra del ganado (caso 17). Así como hubo indígenas que por arriar vacas hasta la frontera se pasaron de dominio y no volvieron, algo similar pasaba con los negros que se quedaron del lado español (ABNB MyCh GRM $25 \mathrm{XIV}) \cdot{ }^{27}$ La acogida de los fugitivos contrasta con la pertinacia de los jesuitas de antaño; muestra de ello es el borrador normativo de Bartelemí Berdugo al que me referí. Por otro lado, 1770 es un momento de intensificación de la fricción fronteriza porque se fundaron villas y fuertes en la costa portuguesa del río Paraguay y porque se firmó el tratado que señalaría de manera definitiva los límites entre ambos imperios, legitimando la ocupación portuguesa. Los expedientes formados para investigar las infracciones de los portugueses en los dominios de España están tan a la orden del día como las acusaciones de contrabando contra los curas de los pueblos. Por último, la explotación aurífera en minas que ubicaban al norte de la provincia reforzó este recelo y se tradujo en la indagación a los prófugos sobre las actividades de los portugueses en la frontera, cuya recurrencia se advierte a partir de 1781 (casos 19, 20, 21, 22, 23 y 25, a quienes dieron refugio a cambio de información; unos pocos fueron devueltos, previo 
interrogatorio). Es así como se supo de los estancieros en la orilla castellana del río Paraguay y de la explotación minera de Guarayu. La acogida de los fugitivos parece haber pretendido resarcir el avance portugués en la frontera y no tardó en provocar el reclamo de las autoridades portuguesas. En 1782, el capitán general de Mato Grosso Luis Albuquerque requirió la devolución de los esclavos fugitivos en nombre del resguardo del derecho de sus propietarios. En la misma carta, y en respuesta a los reclamos españoles por los indígenas que se habían pasado a Portugal, argumentaba que los indígenas podían elegir de qué corona ser vasallos porque eran hombres libres (AGN 2). Un español que visitó Casalvasco en 1783, supo resumir esta disputa al afirmar que los portugueses atraían y retenían en sus tierras a los indígenas de Chiquitos y de Mojos por el "resentimiento de los muchos negros que profugan del poder de ellos y no vuelven a su distrito haciendo de este modo represalias de indios por negros" (ABNB MyCh ALP 285).

La lista de casos termina con dos registrados en 1796, tres de 1801 y el último, mencionado en una certificación de servicios del gobernador de Chiquitos entre 1801 y 1806, redactada en 1808. Con excepción del último, es difícil no especular con respecto a la correlación de todos ellos con los enfrentamientos contemporáneos entre España y Portugal y, en especial, con el conflicto luso-español de 1801 y su corolario americano: los ataques recíprocos a los fuertes de Nueva Coimbra y de San Carlos.

En suma, el análisis de los datos que constan en el registro de los fugitivos en los dominios de España no puede prescindir de las circunstancias históricas reseñadas, ya que permiten poner en evidencia y en contexto el sesgo de la información disponible en los documentos. Sin embargo, que ésta sea sesgada no impide su sistematización, estudio, descripción y análisis. Los resultados presentados aquí permiten dar cuenta de una realidad - la de los fugitivos portugueses en dominios españoles - hasta ahora desconocida, no solo por la ausencia de investigaciones al respecto, sino también por la extensión del paradigma jesuítico a la interpretación del período post-jesuítico en Chiquitos. Tal como fue señalado en otros trabajos, la condición fronteriza de la gobernación de Chiquitos tiene tanto o más peso que el legado jesuítico en las dinámicas políticas y socioculturales del período colonial tardío (Martínez, 2017a, 2018b). Como se desprende de lo expuesto, fueron la condición y la competencia fronteriza entre dos imperios que aceptaban por igual el régimen esclavista las que determinaron la buena acogida de los fugitivos. A lo que este relevamiento sobre negros fugitivos agrega: Chiquitos no es reductible a lo 
indígena: los afrodescendientes dejaron una marca, cuando menos, en el registro documental.

\section{CONSIDERACIONES FINALES}

Con material apenas explorado hasta el presente, los datos expuestos aquí reafirman una realidad lógica y evidente: los fugitivos y las fronteras son indisociables. También permiten echar luz sobre una situación tardo-colonial imaginable pero parcamente conocida, como es la de los fugitivos de los dominios de Portugal en tierras españolas. Así, la problemática de los negros esclavos de Mato Groso, hasta ahora especialmente asociada con la etnogénesis quilombola y la dinámica social de los mocambos, se complementa con esta otra, de corolarios sociales contemporáneos tal vez menos visibles, pero de igual validez en el pasado en lo que respecta a las estrategias activas de evasión. La descripción y la interpretación de los datos que llenan estas páginas ofrecen un estudio exhaustivo de los documentos que conjuga la perspectiva de los fugitivos con el escenario fronterizo en el que se movían.

Además, del ejercicio desplegado en estas páginas se desprenden dos cuestiones procedimentales y hermenéuticas a destacar. Por un lado, una actualización de una clásica cuestión metodológica y heurística de la historiografía: el carácter fragmentario de la información sobre un actor tan subalterno como los negros en Chiquitos se debe a la alteridad de quienes la registraron y a la divergencia entre sus respectivas agendas. Esto, que es una constante para quienes nos dedicamos a estudiar a aquellos actores sociales que no produjeron evidencia sobre sí mismos, hace que la información con la que contamos sea particularmente dispersa. Tal dispersión tal vez sea reparable si imaginamos los intereses e inquietudes de los colonizadores para conjeturar en qué situaciones pueden aparecer referencias sobre los subalternos estudiados. En este sentido, una nueva indagación en los documentos del lado portugués a la luz de la evidencia presentada en estas páginas y la búsqueda de información en fuentes de regiones aledañas, tales como Charcas, Mojos y Santa Cruz se perfilan como opciones posibles para intentar completar la trayectoria de los fugitivos identificados aquí.

Por otra parte, el sesgo que les impone a los investigadores la definición de problemáticas desde una perspectiva local, nacional y contemporánea exige un pronunciamiento. La investigación y el conocimiento del pasado no pueden quedar sujetos a la compartimentación de la evidencia impuesta por la herencia colonial y por los límites entre los Estados nacionales modernos. Es trabajo y 
obligación del historiador empatizar con el pasado que estudia, trascender esas fronteras y pensar en los espacios y las dinámicas sociales como fenómenos que van más allá de los límites internacionales actuales. En su defecto, la colaboración entre investigadores de diversas procedencias se impone. Este trabajo pretende ser un paso en ese sentido.

\section{FUENTES PRIMARIAS}

\section{ABNB - Archivo y Biblioteca Nacionales de Bolivia}

ABNB ALP MyCh - Audiencia de La Plata Mojos y Chiquitos

ABNB MyCh ALP 10. Expediente formado en virtud de las introducciones que realizan la nación portugueses en las provincias del Paraguay, Tucumán y Santa Cruz de la Sierra, 1739-1766.

ABNB MyCh ALP 97. Expediente formado por testimonios de cartas escritas por don Antonio Aymerich y Villajuana, que tratan de varios asuntos, entre ellos el comercio ilícito de los portugueses, esclavos portugueses y otros, 1772-1774.

ABNB MyCh ALP 253. Expediente obrado en virtud de las infracciones cometidas por los portugueses sobre los límites de España respecto de los dominios lusitanos, 1790-1791.

ABNB MyCh ALP 285. Expediente formado en virtud de los acontecimientos ocurridos en la frontera de la provincia Chiquitos, 1792.

ABNB GRM MyCh - Gabriel René Moreno Mojos y Chiquitos

ABNB MyCh GRM 24 IV. Reglamento para la observancia de los jueces, curas y vicario de la provincia de Chiquitos, expedido por el obispo de Santa Cruz de la Sierra en cuanto a su gobierno temporal, 1769.

ABNB MyCh GRM 25 XIV. Documentos que demuestran el absoluto predominio de los curas en los pueblos de la provincia de Chiquitos, 1779-1783.

ABNB MyCh GRM 26 X. Declaración de Juan Perera, moreno de Mato Grosso. Se adjunta una carta de Alejandro Salvatierra. Ambos documentos se refieren al manejo clandestino de los portugueses y a la usurpación de terrenos, 1784.

ABNB MyCh GRM 26 XXV. Expediente promovido en virtud del ingreso y establecimiento clandestino de portugueses en los pueblos de Chiquitos, 1780-1782. 
ABNB MyCh GRM 28 VIII. Documentos correspondientes al informe presentado por el gobernador de Chiquitos en respuesta al que le dirigió el obispo de Santa Cruz, acerca del Nuevo Plan de Gobierno, 1789-1791.

ABNB MyCh GRM 34 IX. Expediente obrado sobre la apertura de un camino entre Chiquitos y Mojos, a través de la reducción de Guarayos, 1807-1809.

ABNB GRM MyCh 39 XXXIV. Borradores de informes relacionados al gobierno y administración de don Juan Barthelemí Verdugo, 1807.

\section{AGN - Archivo General de la Nación (Argentina)}

AGN Sala IX Legajo 7-1-6: División Colonia Sección Gobierno, Gobierno de Santa Cruz

(AGN 1) Documentos relativos al caso de Rosalía Joaquina y Juan Diego Barros Terra, fugitivos de Portugal, Cuiabá / Santa Cruz, 1780-178

AGN Sala IX Legajo 20-6-7: División Colonia Sección Gobierno, Gobierno de Chiquitos

(AGN 2) Carta de Luis Alburquerque Melo Pereira Cáceres al gobernador de Chiquitos, 25/10/1782.

(AGN 3) Carta del gobernador de Chiquitos José Ayarza al virrey del Río de la Plata Pedro Melo de Portugal, San Rafael de Chiquitos, 25/7/1796.

(AGN 4) Carta del gobernador de Chiquitos José Ayarza al virrey del Río de la Plata Pedro Melo de Portugal, San José de Chiquitos, 30/9/1796.

(AGN 5) Carta del gobernador de Chiquitos Miguel Riglos al virrey Joaquín del Pino, Santa Ana, 26/9/1801.

(AGN 6) Declaración en testimonio de negros fugados a Chiquitos, tomada por Francisco Xavier de Velasco, 26/10/1801.

AGN LAMAS Legajo 30/2633

(AGN 7) Carta de Barthelemí Berdugo al virrey del Río de la Plata Juan José Vértiz, 30/9/1782.

(AGN 8) Carta de los soldados Gerónimo Bejarano y José Miguel Castro al gobernador de Chiquitos Barthelemí Berdugo, San Xavier de Chiquitos, 28/10/1782.

LEYES DE INDIAS. Disponibles en: http://www.leyes.congreso.gob.pe/leyes_indias.aspx.

\section{REFERENCIAS}

AMADO, Janaína; ANZAI, Leny Caselli (org.). Anais de Vila Bela 1734-1789. Cuiabá: Ed. UFMT: Carlini \& Caiato, 2006. 
ARRUTI, José Maurício A. A emergência dos 'remanescentes': notas para o diálogo entre indígenas e quilombolas. Mana, Rio de Janeiro: Museu Nacional da Universidade Federal do Rio de Janeiro, v. 3, n. 2, p. 7-38, 1997.

BANDEIRA, Maria de Lourdes. Território negro em espaço branco: estudo antropologico de Vila Bela. São Paulo: Brasiliense, 1988.

BLOCK, David. La cultura reduccional de los llanos de Mojos: tradición autóctona, empresa jesuitica y política civil, 1660-1880. Sucre: Historia Boliviana, 1997.

CARVALHO, Francismar Alex L. de. Lealdades negociadas: povos indígenas e a expansão dos impérios ibéricos nas regiões centrais da América do Sul (segunda metade do século XVIII). 2012. Tese (Doutorado em História Econômica) FFLCH, Universidade de São Paulo. São Paulo, 2012.

CARVALHO, Francismar Alex L. de. Rivalidade imperial e comércio fronteiriço: aspectos do contrabando entre as missões espanholas de Mojos e Chiquitos e a capitania portuguesa de mato Grosso (c. 1767-1800). Antíteses, Londrina: Universidade Estadual de Londrina, v. 4, n. 8, p. 595-630, 2011.

CLERET DE LANGAVANT, Benita Herreros. Portugueses, españoles y mbayá en el alto Paraguay. Dinámicas y estrategias de frontera en los márgenes de los imperios ibéricos (1791-1803). Nuevo Mundo Mundos Nuevos [online], Debates, online 4 Nov. 2012. Disponible en: http://nuevomundo.revues.org/64467. Acceso el 27 sept. 2015.

COELHO, Felipe Joseph N. Memórias Chronológicas da capitania de Mato Grosso, principalmente da Provedoria de Fazenda Real e Intendência do Ouro. Revista trimensal de História e Geographia, Rio de Janeiro, Tomo XIII, p. 137-199. 1850 [c. 1779].

CORREA FILHO, Virgílio. História de Mato Grosso. Rio de Janeiro: Instituto Nacional do Livro, 1969.

CORTESÃO, Jaime. Alexandre de Gusmão e o Tratado de Madrid. 2 v. Rio de Janeiro: Ministério das Relações Exteriores, 1952.

DESCHAMPS CHAPEAUX, Pedro. Los cimarrones urbanos. La Habana: Editorial de Ciencias Sociales, 1983.

GOMES, Flávio dos Santos. A hidra e os pântanos: quilombos e mocambos no Brasil (sécs. XIX-XX). 1997. Tese (Doutorado em História) - IFCH, Universidade Estadual de Campinas (Unicamp). Campinas, 1997. Disponible en: http://repositorio. unicamp.br/jspui/handle/REPOSIP/280897.

GOMES, Flávio dos Santos. Indígenas, africanos y comunidades de fugitivos en la Amazonia colonial. Historia y Espacio, Cali: Universidad del Valle, v. 6, n. 34, p. 201-228, 2010.

HENRIQUE, Márcio Couto; ALONSO, José Luiz Ruiz-Peinado; SANTOS, Josely Cardoso dos. Indios y negros: conflicto y solidaridad en la frontera amazónica, siglo 
XIX. Boletín Americanista, Barcelona: Universitat de Barcelona, v. 75, n. 2, p. 93 111, 2017.

KELLEY, Sean. "México in his Head": Slavery and the Texas-Mexico Border, 18101860. Journal of Social History, Oxford: Oxford University Press, v. 37, n. 3, p. 709-723, 2004.

LAVIÑA GÓMEZ, Javier. Resistencias afroamericanas y otros cimarrones. Anuario IEHS - Instituto de Estudios Histórico Sociales, Tandil: Universidad del Centro de la Provincia de Buenos Aires, n. 10, p. 253-265, 1995.

MACHADO, Maria Fátima R. Quilombos, cabixis e caburés: índios e negros em Mato Grosso no século XVIII. In: REUNIÃO BRASILEIRA DE ANTROPOLOGIA (ABA), 25., 2006. Anais... GT 48. Disponible en: www.ifch.unicamp.br/ihb/Textos/ GT48Fatima.pdf.

MAEDER, Ernesto J. A. Los problemas de límites entre España y Portugal en el Río de la Plata. (Cuadernos Docentes 4 y 5). 2 v. Resistencia: Instituto de Investigaciones Geohistóricas, Facultad de Humanidades, UNNE, 1986.

MARTÍNEZ, Cecilia. Cavaleiros contra flecheros: Treinta años de guerra chiquito-guaycurú en la frontera luso-española (1763-1793). Americanía, Sevilla: Universidad Pablo de Olavide, v. 5, p. 328-367, $2017 \mathrm{~b}$.

MARTÍNEZ, Cecilia. Una etnohistoria de Chiquitos, más allá del horizonte jesuítico. Cochabamba: Itinerarios: Instituto de Misionología, 2018a.

MARTÍNEZ, Cecilia. Indios, blancos y negros: relaciones interétnicas en la frontera de Chiquitos con Mato Grosso (siglo XVIII). Memoria Americana, Buenos Aires: Universidad de Buenos Aires, v. 25, n. 2, p. 69-94, 2017a.

MARTÍNEZ, Cecilia. La más pobre entre las pobres: para una crítica de los estudios sobre la Chiquitania (oriente boliviano). Revista de Antropologia, São Paulo: Universidade de São Paulo, v. 61, n. 1, p. 298-328, 2018 b.

MEIRELES, Denise Maldi. Guardiães da fronteira: Rio Guaporé, século XVIII. Rio de Janeiro: Vozes, 1989.

MENDONÇA, Marcos C. de. Rios Guaporé e Paraguai: primeiras fronteiras definitivas do Brasil. Rio de Janeiro: Biblioteca Reprográfica Xerox, 1985.

NAVARRETE PELÁEZ, María Cristina. El cimarronaje: una alternativa de libertad para los esclavos negros. Historia Caribe, Barranquilla: Universidad del Atlántico, v. 6, p. 89-98, 2001.

NICHOLS, James David. The Line of Liberty: Runaway Slaves and Fugitive Peons in the Texas-Mexico Borderlands. The Western Historical Quarterly, Oxford: The Western History Association, v. 44, n. 4, p. 413-433, 2013.

PEREIRA, Ione A. M. C.; PUHLL, João I.; CHAVES, Otávio R. Índios de Mojo e Chiquitos no contexto colonial ibérico do século XVI ao XVIII. Territórios \& Fronteiras, Cuiabá: Universidade Federal de Mato Grosso, v. 5, n. 2, p. 32-59, 2012. 
PRICE, Richard. Sociedades cimarronas: comunidades esclavas rebeldes en las Américas. México: Siglo XXI, 1981.

QUARLERI, Lía. Rebelión y guerra en las fronteras del Plata: guaraníes, jesuitas e imperios coloniales. Buenos Aires: Fondo de Cultura Económica, 2009.

RODRIGUES, Bruno Pinheiro. 'Aruaquização': para outra possível leitura do quilombo Grande. Territórios \& Fronteiras, Cuiabá: Universidade Federal de Mato Grosso, v. 9, n. 1, p. 285-302, 2016b.

RODRIGUES, Bruno Pinheiro. O trânsito de cativos do Oeste da América portuguesa para espanhola: fugas, sequestros e a busca por liberdade (século XVIII). Fronteiras - Revista de História, Dourados: Universidade Federal de Mato Grosso do Sul, v. 18, n. 31, p. 357-374, 2016a.

SENA, Ernesto C. de. De colônias a início dos Estados nacionais: considerações sobre as fronteiras entre a Bolívia e o Brasil. Territórios \& Fronteiras, Cuiabá: Universidade Federal de Mato Grosso, v. 5, p. 114-130, 2012.

SENA, Ernesto C. de. Fugas e reescravizações em região fronteiriça - Bolívia e Brasil nas primeiras décadas dos Estados nacionais. Estudos Ibero-Americanos, Porto Alegre: PUCRS, v. 39, n. 1, p. 82-98, 2013.

SERNA, Juan Manuel de la. Los cimarrones en la sociedad novohispana. In: SERNA, Juan Manuel de la (ed.). De la libertad y la abolición. México: Centro de estudios mexicanos y centroamericanos, 2010. p. 83-109. Disponible en: https://books.openedition.org/cemca/1606.

SOTOMAYOR, Walter Awad. Relaciones Brasil Bolivia: la definición de las fronteras. La Paz: Ceres: Plural, 2013.

SOUZA LORDELO, Monique Cristina de. Escravos negros na fronteira entre Brasil e Bolívia. In: SIMPÓSIO NACIONAL DE HISTÓRIA - ANPUH, 26., 2011, São Paulo. Anais... Disponible en: http://www.snh2011.anpuh.org/site/ anaiscomplementares\#M.

VOLPATO, Luiza Rios R. Quilombos em Mato Grosso: resistência negra em área de fronteira. In: REIS, João José; GOMES, Flávio dos Santos. (ed.). Liberdade por um fio: história dos quilombos no Brasil. São Paulo: Companhia das Letras, 1996. p. 213-239.

\section{NOTAS}

${ }^{1}$ Una primera versión de este trabajo fue presentada en las III Jornadas de Antropología, Historia y Arqueología de las Tierras Bajas (Santa Cruz de la Sierra, 7 y 8 nov. 2018). Agradezco a Verone Cristina da Silva y Domingos Savio da Cunha Garcia por los comentarios. También agradezco los comentarios y las sugerencias de los evaluadores anónimos. 
2 Sobre la colonización de Mato Grosso véase la ineludible Historia de Mato Grosso (CORREA FILHO, 1969).

${ }^{3}$ Sobre la situación sociohistórica de las comunidades rurales negras de Mato Grosso, véase BANDEIRA, 1988; sobre los quilombos de Mato Grosso, VOLPATO, 1996. En GOMES, 1997, un estudio sobre la dinámica interna de los mocambos y su relación con el exterior. Sobre la relación entre negros e indígenas véase: MACHADO, 2006; RODRIGUES, 2016b.

${ }^{4}$ SOUZA LORDELO (2011) y RODRIGUES (2016a) se basan en un solo expediente proveniente del lado español (ver caso 28 del cuadro) y en correspondencia oficial entre las gobernaciones limítrofes que se refiere de manera genérica a las fugas, sin identificar a los fugitivos.

${ }^{5}$ Estos ocurrieron en concomitancia con los que ocurrían en otros puntos de contacto entre ambos imperios, como el Río de la Plata, el Río Grande, y el río Uruguay. Al respecto, véanse, por ejemplo: CORTESÃO, 1952; MAEDER, 1986; QUARLERI, 2009.

${ }^{6}$ Los casos 1 a 7 fueron registrados en ABNB MyCh ALP 10.

${ }^{7}$ ABNB MyCh ALP 97.

${ }^{8}$ ABNB MyCh ALP 253 y MyCh GRM 28 VIII.

${ }^{9}$ ABNB MyCh GRM 24 IV.

${ }^{10}$ Los casos 11 a 15 están en ABNB MyCh GRM 24 IV.

${ }^{11}$ ABNB MyCh ALP 253.

${ }^{12}$ ABNB MyCh GRM 25 XIV.

${ }^{13}$ AGN 1.

${ }^{14}$ Casos 19 y 20 en ABNB MyCh ALP 253.

${ }^{15}$ ABNB MyCh GRM 26 X.

${ }^{16}$ ABNB MyCh GRM 26 XXV.

${ }^{17}$ AGN 8.

${ }^{18}$ AGN 7.

${ }^{19}$ AGN 8.

${ }^{20}$ Casos 26 y 27 en AGN 3.

${ }^{21}$ AGN 4.

${ }^{22}$ AGN 5.

${ }^{23}$ AGN 6.

${ }^{24}$ ABNB MyCh GRM 34 IX.

${ }^{25}$ Sobre "cimarrón" como apelativo para negros y esclavos fugitivos en Hispanoamérica, véanse: PRICE, 1981; DESCHAMPS CHAPEAUX, 1983; LAVIÑA GÓMEZ, 1995; NAVARRETE PELÁEZ, 2001; DE LA SERNA, 2010. 
${ }^{26} \mathrm{Al}$ respecto, véase RODRIGUES, 2016b, a propósito de la "aruaquización" del quilombo Grande; sobre la definición étnica de los indígenas integrados en los quilombos de Mato Grosso, MACHADO, 2006. Sobre la fuga de indígenas en comparación con la de los negros y la colaboración de ambos en los mocambos en la capitanía general de Grão-Pará, GOMES, 2010. Como referencia casuística del Estado de Pará en el siglo XIX y antecedente metodológico y conceptual, véase HENRIQUE et al., 2017. La colaboración negro-indígena no es exclusiva de Brasil: en el siglo XIX, la frontera entre México y EEUU también fue terreno fértil para este fenómeno (KELLEY, 2004).

${ }^{27}$ Situaciones similares de evasiones en el contexto de ventas de productos de los amos son reseñadas en casuísticas de la frontera de México con Estados Unidos en el siglo XIX (NICHOLS, 2013).

Artículo recibido el 16 de abril de 2019. Aprobado el 20 de agosto de 2019. 